\title{
Gastrointestinal Hemorrhage Severity Triage: Locally Derived Score May Outperform Existing Scoring Systems
}

\author{
Rangson Chaikitamnuaychok ${ }^{\mathrm{a}}$, Jayanton Patumanond ${ }^{\mathrm{b}, \mathrm{c}}$
}

\begin{abstract}
Background: Scoring tools to predict need for intervention, re-bleeding and mortality of upper gastrointestinal hemorrhage (UGIH) have been developed. It is inconclusive whether these tools are also appropriate for UGIH severity and/or urgency triage. The objective of the study was to compare the performances of the Blatchford score, the Rockall score, and the UGIH score on UGIH severity triage.
\end{abstract}

Methods: Retrospective 3-year data of UGIH patients (2009 - 2011) were collected. Patients were assigned to each of the three scoring systems based on their clinical characteristics required for the scoring systems. The score ranges of each scoring system were transformed into the same scale from 0 to 100 . The score performances were compared by diagnostic indices, graphically presented with area under receiver operating curve (AuROC), discrimination curves, and statistically tested with Chi-squared tests.

Results: When focusing on the diagnostic indices, the local UGIH had similar sensitivity to, but better specificity than the Blatchford score in detecting mild UGIH. The sensitivity was better than and the specificity was less than the Blatchford score in detecting severe UGIH. The local UGIH score was better than the pre-endoscopic Rockall in almost all diagnostic indices. Focusing overall performances, the local UGIH score classified patients non-significantly better than the Blatchford: $89.3 \%$ vs. $87.9 \%$ for mild $(\mathrm{P}=0.243)$, $87.2 \%$ vs. $85.0 \%$ for severe ( $\mathrm{P}=0.092)$, but significantly classified better than the pre-endoscopic Rockall score: $89.3 \%$ vs. $76.4 \%$ for mild $(\mathrm{P}<0.001)$, and $87.2 \%$ vs. $81.2 \%$ for severe $(\mathrm{P}<0.001)$. When exploring the discrimination curves, the Blatchford score classified more patients into the mild categories, and less into the severe cat-

Manuscript accepted for publication April 24, 2015

aDepartment of General Surgery, Kamphaeng Phet Hospital, Kamphaeng Phet 62000, Thailand

bepartment of Clinical Epidemiology and Clinical Statistics, Faculty of Medicine; Center of Excellence in Applied Epidemiology, Thammasat University, Pathum Thani 12120, Thailand

${ }^{\mathrm{c} C}$ Corresponding Author: Jayanton Patumanond, Department of Clinical Epidemiology and Clinical Statistics, Faculty of Medicine; Center of Excellence in Applied Epidemiology, Thammasat University, Pathum Thani 12120, Thailand.Email: jpatumanond@gmail.com

doi: http://dx.doi.org/10.14740/gr652w egories than the local UGIH score. In contrast, the pre-endoscopic Rockall score classified less patients into the mild, but more into the severe than the local UGIH score.

Conclusion: Triaging UGIH patients into three severity levels in order to decide or set for endoscopy should apply the scoring system specifically developed for that purpose. Adopting other scores developed for other purposes may result in under- and/or over-estimations. The local UGIH score classified patients into three severity levels to help indicate endoscopy more efficiently than the Blatchford score and the preendoscopic Rockall score which was developed for different purposes.

Keywords: Clinical prediction rules; Scoring system; Screening; Upper gastrointestinal bleeding; Upper gastrointestinal hemorrhage; Validation

\section{Introduction}

Upper gastrointestinal tract hemorrhage (UGIH) is one of the most common causes of hospital admission. The severity of UGIH varies from mild coffee ground vomiting to massive bleeding (exsanguination) [1]. UGIH severity may be classified by clinical and/or endoscopic criteria [2-11]. In general, "low risk" means re-bleeding $<5 \%$ and/or mortality $<1 \%$ [12]. Limitations of classifying UGIH severity included debates on, whether it is an absolute indication for endoscopy, whether to manage patients as in-patient department (IPD) or out-patient department (OPD) cases, should early endoscopy be advised in every institute, and were classifications based on various techniques and systems disseminated to the other institutes [12]. It is well accepted that emergent endoscopy should be set in patients with unstable hemodynamics. These may include orthostatic hypotension, tachycardia, shock, and/or signs of continued bleeding [13]. However, emergent endoscopy is not normally set on weekends in most hospitals [1]. Non-emergent or non-urgent cases would therefore be postponed to the next available weekdays, or possibly longer for cases requiring semi-elective procedures [1].

Prior to the time of endoscopy, prediction for UGIH severity was important in prognostication for need of hospitalization, and/or need for close monitoring in intensive care units when patients had high risks for re-bleeding [13]. While clini- 
Table 1. Scoring Scheme for the Blatchford Score

\begin{tabular}{|c|c|c|c|}
\hline Item indicators & & Categories & Score \\
\hline \multirow[t]{5}{*}{ BUN (mg/dL) } & & $<18.2$ & 0 \\
\hline & & $18.2-22.3$ & 2 \\
\hline & & $22.4-27.9$ & 3 \\
\hline & & $28-69.9$ & 4 \\
\hline & & $\geq 70$ & 6 \\
\hline \multirow[t]{7}{*}{ Hemoglobin (g/dL) } & Male & $>13$ & 0 \\
\hline & & $12.0-12.9$ & 1 \\
\hline & & $10.0-11.9$ & 3 \\
\hline & & $<10.0$ & 6 \\
\hline & Female & $>12$ & 0 \\
\hline & & $10.0-11.9$ & 1 \\
\hline & & $<10.0$ & 6 \\
\hline \multirow[t]{4}{*}{ Systolic blood pressure (mm Hg) } & & $\geq 110$ & 0 \\
\hline & & $100-109$ & 1 \\
\hline & & $90-99$ & 2 \\
\hline & & $<90$ & 3 \\
\hline \multirow[t]{2}{*}{ Pulse rate (/min) } & & $<100$ & 0 \\
\hline & & $\geq 100$ & 1 \\
\hline \multirow[t]{2}{*}{ Melena } & & Yes & 1 \\
\hline & & No & 0 \\
\hline \multirow[t]{2}{*}{ Syncope } & & Yes & 2 \\
\hline & & No & 0 \\
\hline \multirow[t]{2}{*}{ Hepatic diseases } & & Yes & 2 \\
\hline & & No & 0 \\
\hline \multirow[t]{2}{*}{ Cardiac failure } & & Yes & 2 \\
\hline & & No & 0 \\
\hline
\end{tabular}

cal parameters alone may be sufficient to predict the possibility of management as OPD cases in patients with low risks for re-bleeding [13].

Many researchers had developed and published scoring systems with an objective to discriminate patients with low risks from those with high risks $[3,5,6,8,14]$. The most mentioned and referenced works were the Blatchford score, to predict need for intervention of UGIH [15], and the Rockall score to predict re-bleeding and mortality [5].

We previously developed a local UGIH score (from the data of patients between 2009 and 2010) [16, 17], to triage patients into three severity levels: mild, moderate, and severe [16], based on clinical and laboratory variables. The triaging focused on providing clinical guideline for treatments of UGIH and when to do endoscopy: non-urgent, urgent, and emergent [16]. The developed local UGIH score was internally validated to another independent patient of the following year (from data of patients in 2011) [18]. The local UGIH score performed similarly (both calibration and discrimination) in the development dataset and the validation dataset, and was clinically acceptable [18].

In the present study, we focused on comparing our local UGIH score to the Blatchford score and the pre-endoscopic Rockall score, on their abilities to predict the severity, or urgency of UGIH prior to endoscopy.

\section{Patients and Methods}

\section{Patients}

The UGIH patients were registered in KamphaengPhet Hospital, a university-affiliated tertiary hospital in the northern region of Thailand. We retrieved medical folders of patients who presented to the emergency department with upper gastrointestinal bleeding, between 2009, 2010 and 2011 [16-18]. The ICD-10 keywords for hospital database search were K920hematemesis, K921-melena and K922-gastrointestinal hemorrhage unspecified. 
Table 2. Scoring Scheme for the Pre-Endoscopic Rockall Score

\begin{tabular}{llll}
\hline Item indicators & Categories & Criteria & Score \\
\hline Age (years) & $<60$ & & 0 \\
& $60-79$ & & 1 \\
Shock & $\geq 80$ & & 2 \\
& No shock & SBP $>100 \mathrm{~mm} \mathrm{Hg}$ & 0 \\
& Tachycardia & Pulse $<100 / \mathrm{min}$ & \\
& SBP $>100 \mathrm{~mm} \mathrm{Hg}$ & 1 \\
Hypotension & Pulse $>100 / \mathrm{min}$ & 2 \\
Comorbidity & $\mathrm{SBP}<100 \mathrm{~mm} \mathrm{Hg}$ & 0 \\
& No major comorbidity & & 2 \\
& Cardiac failure & & \\
& Ischemic heart disease & & 3 \\
& Any major comorbidity & & \\
& Renal or liver failure & & \\
\hline
\end{tabular}

\section{Definitions of UGIH severity: an outcome of interest}

We used the following criteria to define UGIH severity. 1) Severe: patients who required surgical interventions to stop bleeding, patients in states of grade 3 and 4 shock [19], and patients who did not survive. 2) Moderate: patients who required endoscopy to stop bleeding (endotherapy), patients with rebleeding, patients in states of grade 1 and 2 shock [19], and patients who required blood transfusion. 3) Mild: patients with no signs of shock, patients who required endoscopy without hemostasis, and patients who did not required any blood transfusions.

Table 3. Scoring Scheme for the Local UGIH Score

\begin{tabular}{lll}
\hline Item indicators & Categories & Score \\
\hline Age (years) & $\geq 60$ & 1 \\
& $<60$ & 0 \\
Pulse (/min) & $\geq 100$ & 1 \\
& $<100$ & 0 \\
Systolic blood pressure (mm Hg) & $<100$ & 10.5 \\
& $\geq 100$ & 0 \\
Hemoglobin (g/dL) & $<10$ & 6 \\
& $\geq 10$ & 0 \\
BUN (mg/dL) & $\geq 35$ & 2 \\
Cirrhosis & $<35$ & 0 \\
& Yes & 2 \\
Hepatic failure & No & 0 \\
& Yes & 4.5 \\
\hline
\end{tabular}

\section{The three scoring systems}

We applied the three scoring systems to the same set of patients to compare their performances. 1) The Blatchford Score, which included clinical and laboratory variables (Table 1) [15]. 2) The pre-endoscopic Rockall criteria, which included only clinical variables (Table 2) [5]. 3) The local UGIH score criteria, which included simple clinical and laboratory variables (Table 3) [18].

\section{Data analysis}

Characteristics of patients with mild, moderate, and severe UGIH were described and compared with parametric or nonparametric tests for trend as appropriate. A UGIH severity was predicted based on the three mentioned systems. The minimum and maximum score points of the three systems were converted to the same minimum and maximum scores $(0$ and 100). Backward calculation was done to obtain standardized score $(0-100)$ for each of the three systems. The performances of the scores in classifying patients into three severity scores were presented with classical diagnostic indices: sensitivity, specificity, predictive value of positive, predictive value of negative, and $\%$ correctly classified, and tested with exact probability. The prediction of the scores was graphically presented with discrimination curves and tested with an area under the receiver operating curve (AuROC).

\section{Results}

Patients in the three severity groups differed according to age, presence of melena, syncope, systolic blood pressure, hemo- 
Table 4. Characteristics of Patients With Upper Gastrointestinal Hemorrhage and Score Distributions

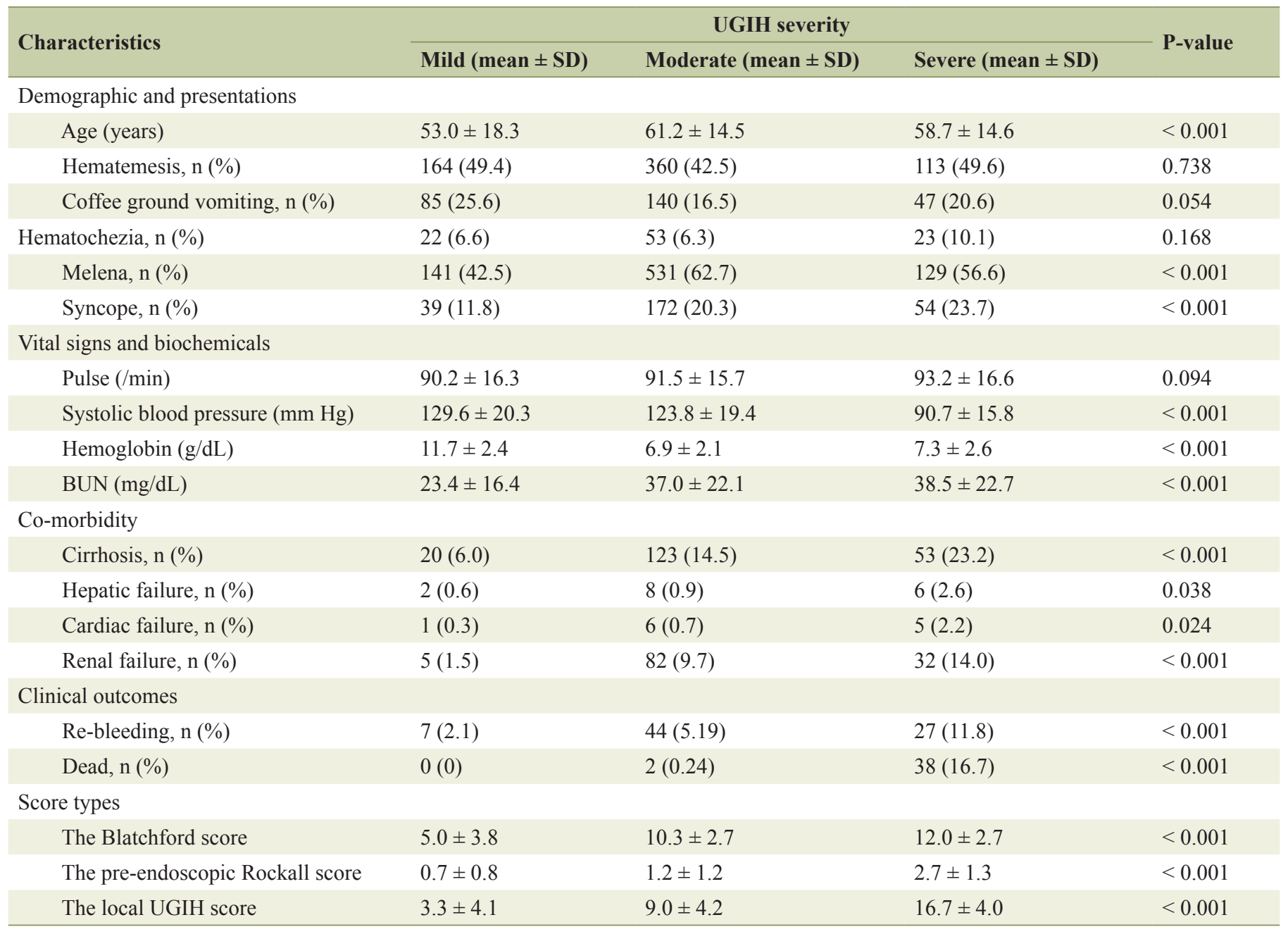

globin, blood urea nitrogen (BUN), presence of cirrhosis, and renal failure.

When the three systems were used to assign scores to each patient in the three severity categories, the mean ( \pm SD) Blatchford scores were $5.0 \pm 3.8$ in mild group, $10.3 \pm 2.7$ in moderate group, and $12.0 \pm 2.7$ in severe group $(\mathrm{P}<0.001)$. The mean $( \pm \mathrm{SD})$ pre-endoscopic Rockall scores were $0.7 \pm$ $0.8,1.2 \pm 1.2$, and $2.7 \pm 1.3(\mathrm{P}<0.001)$, and the mean $( \pm \mathrm{SD})$ local UGIH severity scores were $3.3 \pm 4.1,9.0 \pm 4.2$, and 16.7 $\pm 4.0(\mathrm{P}<0.001)$ (Table 4).

The local UGIH score discriminated mild UGIH patients from the remaining patients correctly in $86.8 \%$, similar to the Blatchford score $(87.3 \%)(\mathrm{P}=0.693)$, but significantly better than the pre-endoscopic Rockall $(70.0 \%)(\mathrm{P}<0.001)$.

The local UGIH score also discriminated severe UGIH patients from the other two categories in $90.5 \%$, better than the Blatchford score $(74.6 \%)(\mathrm{P}<0.001)$, and better than the pre-endoscopic Rockall score $(86.1 \%)(\mathrm{P}<0.001)$.

When focusing on the diagnostic indices, the local UGIH had similar sensitivity to, but better specificity than the Blatchford score in detecting mild UGIH. The sensitivity was better than and the specificity was less than the Blatchford score in detecting severe UIGH. However, the local UGIH score was better than the pre-endoscopic Rockall in almost all diagnostic indices.

Focusing overall performances, the local UGIH score classified patients non-significantly better than the Blatchford: $89.3 \%$ vs. $87.9 \%$ for mild ( $\mathrm{P}=0.243$ ), $87.2 \%$ vs. $85.0 \%$ for severe $(\mathrm{P}=0.092)$, but significantly classified better than the pre-endoscopic Rockall score: $89.3 \%$ vs. $76.4 \%$ for mild ( $\mathrm{P}<$ $0.001)$, and $87.2 \%$ vs. $81.2 \%$ for severe $(\mathrm{P}<0.001)$ (Table 5$)$.

When exploring into the discrimination curves, the Blatchford score classified more patients into the mild categories, and less into the severe categories than the local UGIH score. In contrast, the pre-endoscopic Rockall score classified less patients into the mild, but more into the severe that the local UGIH score (Fig. 1).

\section{Discussion}

With the aim of predicting recurrent bleeding, the Blatchford 
Table 5. Discriminative and Diagnostic Indices of Bradford Score, Rockall Score and UGIH Score

\begin{tabular}{|c|c|c|c|c|c|}
\hline \multirow[b]{2}{*}{ Indices } & \multicolumn{3}{|c|}{ Score types } & \multicolumn{2}{|c|}{ P-value } \\
\hline & $\begin{array}{l}\text { Bradford } \\
\text { score }^{1}\end{array}$ & $\begin{array}{l}\text { Rockall } \\
\text { score }^{2}\end{array}$ & $\begin{array}{l}\text { UGIH } \\
\text { score }^{3}\end{array}$ & 3 vs. 1 & 3 vs. 2 \\
\hline \multicolumn{6}{|c|}{ Discrimination: AuROC (\%) } \\
\hline Mild vs. rest & 87.3 & 70.0 & 86.8 & 0.693 & $<0.001$ \\
\hline Severe vs. rest & 74.6 & 86.1 & 90.5 & $<0.001$ & $<0.001$ \\
\hline \multicolumn{6}{|l|}{ Diagnostic } \\
\hline \multicolumn{6}{|l|}{ Sensitivity (\%) } \\
\hline Mild vs. rest & 96.8 & 100 & 95.7 & 0.125 & $<0.001$ \\
\hline Severe vs. rest & 9.2 & 16.2 & 62.3 & $<0.001$ & $<0.001$ \\
\hline \multicolumn{6}{|l|}{ Specificity (\%) } \\
\hline Mild vs. rest & 59.0 & 0 & 68.7 & $<0.001$ & $<0.001$ \\
\hline Severe vs. rest & 99.7 & 94.1 & 92.0 & $<0.001$ & 0.029 \\
\hline \multicolumn{6}{|l|}{ PPV $(\%)$} \\
\hline Mild vs. rest & 88.4 & 76.4 & 90.8 & 0.037 & $<0.001$ \\
\hline Severe vs. rest & 84.0 & 34.9 & 60.2 & $<0.001$ & $<0.001$ \\
\hline \multicolumn{6}{|l|}{ NPV $(\%)$} \\
\hline Mild vs. rest & 85.2 & - & 83.2 & 0.146 & - \\
\hline Severe vs. rest & 85.0 & 85.3 & 92.7 & $<0.001$ & $<0.001$ \\
\hline \multicolumn{6}{|c|}{ Correctly classified (\%) } \\
\hline Mild vs. rest & 87.9 & 76.4 & 89.3 & 0.243 & $<0.001$ \\
\hline Severe vs. rest & 85.0 & 81.2 & 87.2 & 0.092 & $<0.001$ \\
\hline
\end{tabular}

score was developed from 1,748 patients in Glasgow, Scotland, based on clinical and laboratory data, without endoscopy, and was validated for the risks (need) of clinical intervention $[15,20]$. The score ranged from 0 to 23 , and higher score represented higher risks [21]. The Rockall score was developed based on both clinical and endoscopic criteria, from 4,185 patients from 79 hospitals in the UK, focusing the prediction

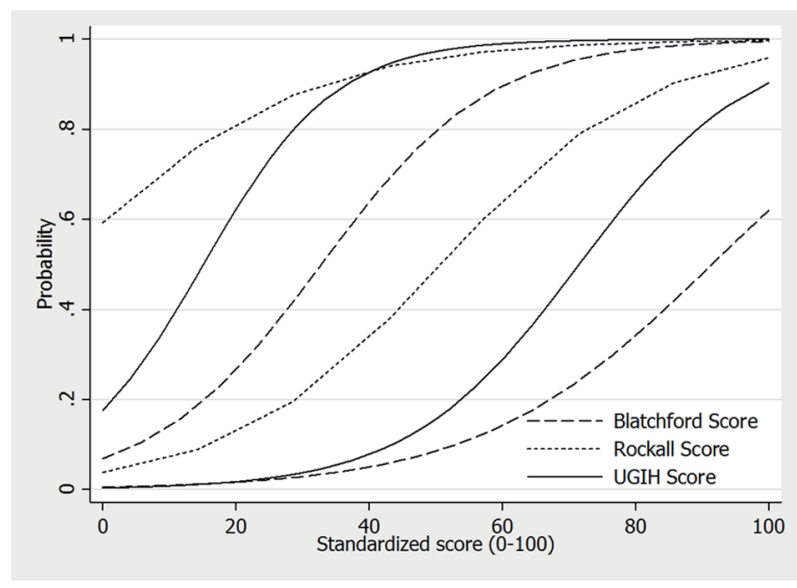

Figure 1. Discrimination of upper gastrointestinal hemorrhage patients into mild, moderate and severe, by the Blatchford score, the pre-endoscopic Rockall score, and the local UGIH score. Original scores were transformed into the same scaled standardized score from 0 to 100. for re-bleeding and mortality. The score ranged from 0 to 7 in the clinical Rockall score, and 0 - 11 in the complete Rockall score [21]. It was recommended that low clinical Rockall score could be used as a guideline to discharge the patients safely and to appoint as OPD cases for elective endoscopy, in order to reasonably allocate resources [22].

In the original report concerning the Blatchford score [15], score 0 would signify low risks for adverse clinical outcomes, with $96 \%$ sensitivity and $32 \%$ specificity [15]. However, an external validation yielded different results with $100 \%$ sensitivity and $3.4 \%$ specificity [23]. When the cutoff value was shifted to $2,87 \%$ of the patients with low risks were set for emergent endoscopy, reflecting an over-diagnosis [23]. On validation, the clinical Rockall score at 0 observed no adverse outcomes, at scores 1 - 3, although there were no adverse outcomes observed, blood transfusion was observed in $29 \%$, while $21 \%$ re-bleeding, $5 \%$ surgery and $10 \%$ death were observed in score $>3$ [22]. For the Rockall score, an external validation yielded poorer calibration fit in the prediction for re-bleeding than mortality. When concerning discrimination, an AuROC was lower for prediction of re-bleeding, but higher for mortality [24].

Some studies reported better performances of the Blatchford score over the pre-endoscopic Rockall score in predicting need for endoscopy [25], but with low specificity (6.3\%) [25]. In Thailand, researchers claimed that the Blatchford score predicted high risk for re-bleeding and mortality better than the 
clinical Rockall score [26], but the score boundaries between low risks and high risks were narrow in both scoring systems. Using 0 score for low risks and $>0$ for high risks classified the majority of patients as "high risk" [16] when in fact most of UGIH cases do not require endoscopic treatment, surgery, blood transfusion, and re-bleeding or death were small $[5,27$, 28]. More resources would therefore be consumed unnecessarily under those circumstances [16].

Among many publications on clinical prediction rules for risk stratification of UGIH [5, 14, 15, 29-32], no single scores were widely adopted to be used in routine clinical practice [33]. This might be explained by insufficient validation [14, $15,31,32]$, low clinical applicability $[5,29,30]$, or complexities $[5,8,15,32]$. To refine UGIH classification to make it more flexible, and due to the fact that emergent endoscopy may not be readily available for every patient in all hospitals, as in Thailand or in other countries, classifying UGIH patients into three categories should enhance the practicability to selectively set for endoscopy within $24 \mathrm{~h}$, especially for patients with risk risks [16].

We agreed that the Blatchford score may be suitable in case of need for intervention (blood transfusion, endoscopic hemostasis, or surgery) $[1-15,20-26]$, but in classifying patients into three urgency levels to set priority for endoscopy, the Blatchford may not be suitable, as some moderately severe patients would be classified as mild (under-estimate), and some severe patients would be classified as moderate (under-estimate). We also agreed that the pre-endoscopic Rockall score [5] may be suitable in the prediction for poor clinical outcomes (re-bleeding or death), but it may not be suitable for classifying UGIH severity, as some mildly severe patients would be classified as moderate (over-estimate), and some moderately severe patients would be classified as severe (over-estimate).

Adoption of a score developed for one condition to be used in another condition may be inappropriate. Choosing the cutoff point not previously mentioned in the original scoring system may cause clinically meaning misclassifications. In this report, we used AuROC to avoid an arbitrary cutoff point, and analyze sensitivity and specificity from a logistic function with the same probability of 0.5 in all three systems, and found that both AuROC and \% correctly classified were in similar directions, indicating that the statistical analysis was unlikely to be biased.

The findings in this report led to the conclusion that clinical score development should be conducted in the context of clinical objectives. Any cross-contextual uses of clinical score are not likely to be successful and could lead to invalid results. It should be emphasized that the score developed in one own settings may be more suitable than adopting scores developed from another settings with different population mix.

\section{Conclusions}

Triaging UGIH patients into three severity levels in order to decide or set for endoscopy should apply the scoring system specifically developed for that purpose. Adopting other scores developed for other purposes may result in under- and/or overestimations. The present report clearly demonstrated that the local UGIH score classified patients into three severity levels to help indicate endoscopy more efficiently than the other two existing scoring systems (the Blatchford score and the preendoscopic Rockall score) which were developed for different purposes.

\section{Acknowledgement}

The authors wish to thank Pichai Siripornpanich, MD, the Director of Kamphaeng Phet Hospital for his strong support.

\section{Grant and Conflict of Interests}

None declared.

\section{Abbreviations}

UGIH: upper gastrointestinal hemorrhage; AuROC: area under receiver operating characteristic curve; IPD: in-patient department; OPD: out-patient department

\section{References}

1. Stanley AJ, Ashley D, Dalton HR, Mowat C, Gaya DR, Thompson E, Warshow U, et al. Outpatient management of patients with low-risk upper-gastrointestinal haemorrhage: multicentre validation and prospective evaluation. Lancet. 2009;373(9657):42-47.

2. Longstreth GF, Feitelberg SP. Outpatient care of selected patients with acute non-variceal upper gastrointestinal haemorrhage. Lancet. 1995;345(8942):108-111.

3. Longstreth GF, Feitelberg SP. Successful outpatient management of acute upper gastrointestinal hemorrhage: use of practice guidelines in a large patient series. Gastrointest Endosc. 1998;47(3):219-222.

4. Rockall TA, Logan RF, Devlin HB, Northfield TC. Variation in outcome after acute upper gastrointestinal haemorrhage. The National Audit of Acute Upper Gastrointestinal Haemorrhage. Lancet. 1995;346(8971):346-350.

5. Rockall TA, Logan RF, Devlin HB, Northfield TC. Risk assessment after acute upper gastrointestinal haemorrhage. Gut. 1996;38(3):316-321.

6. Rockall TA, Logan RF, Devlin HB, Northfield TC. Selection of patients for early discharge or outpatient care after acute upper gastrointestinal haemorrhage. National Audit of Acute Upper Gastrointestinal Haemorrhage. Lancet. 1996;347(9009):1138-1140.

7. Rockall TA, Logan RF, Devlin HB, Northfield TC. Influencing the practice and outcome in acute upper gastrointestinal haemorrhage. Steering Committee of the National Audit of Acute Upper Gastrointestinal Haemorrhage. Gut. 1997;41(5):606-611.

8. Hay JA, Maldonado L, Weingarten SR, Ellrodt AG. Prospective evaluation of a clinical guideline recommending 
hospital length of stay in upper gastrointestinal tract hemorrhage. JAMA. 1997;278(24):2151-2156.

9. Lee JG, Turnipseed S, Romano PS, Vigil H, Azari R, Melnikoff N, Hsu R, et al. Endoscopy-based triage significantly reduces hospitalization rates and costs of treating upper GI bleeding: a randomized controlled trial. Gastrointest Endosc. 1999;50(6):755-761.

10. Bjorkman DJ, Zaman A, Fennerty MB, Lieberman D, Disario JA, Guest-Warnick G. Urgent vs. elective endoscopy for acute non-variceal upper-GI bleeding: an effectiveness study. Gastrointest Endosc. 2004;60(1):1-8.

11. Cipolletta L, Bianco MA, Rotondano G, Marmo R, Piscopo R. Outpatient management for low-risk nonvariceal upper GI bleeding: a randomized controlled trial. Gastrointest Endosc. 2002;55(1):1-5.

12. Gralnek IM. Outpatient management of "low-risk" nonvariceal upper GI hemorrhage. Are we ready to put evidence into practice? Gastrointest Endosc. 2002;55(1):131134.

13. Eisen GM, Dominitz JA, Faigel DO, Goldstein JL, Kalloo AN, Petersen BT, Raddawi HM, et al. An annotated algorithmic approach to upper gastrointestinal bleeding. Gastrointest Endosc. 2001;53(7):853-858.

14. Hay JA, Lyubashevsky E, Elashoff J, Maldonado L, Weingarten SR, Ellrodt AG. Upper gastrointestinal hemorrhage clinical--guideline determining the optimal hospital length of stay. Am J Med. 1996;100(3):313-322.

15. Blatchford O, Murray WR, Blatchford M. A risk score to predict need for treatment for upper-gastrointestinal haemorrhage. Lancet. 2000;356(9238):1318-1321.

16. Chaikitamnuaychok R, Patumanond J. Upper gastrointestinal hemorrhage: development of to the severity score. Gastroenterol Res. 2012;5(6):219-226.

17. Chaikitamnuaychok R, Patumanond J. Clinical risk characteristics of upper gastrointestinal hemorrhage severity: A multivariable risk analysis. Gastroenterol Res. 2012;5(4):149-155.

18. Chaikitamnuaychok R, Patumanond J. Upper gastrointestinal hemorrhage: Validation of the severity score. Gastroenterol Res. 2013;6(2):56-62.

19. Committee on Trauma, American College of Surgeons. ATLS: Advanced Trauma Life Support Program for Doctors. 8th ed. Chicago: American College of Surgeons, 2008.

20. Chen IC, Hung MS, Chiu TF, Chen JC, Hsiao CT. Risk scoring systems to predict need for clinical intervention for patients with nonvariceal upper gastrointestinal tract bleeding. Am J Emerg Med. 2007;25(7):774-779.

21. Gralnek IM, Barkun AN, Bardou M. Management of acute bleeding from a peptic ulcer. N Engl J Med. 2008;359(9):928-937.
22. Tham TC, James C, Kelly M. Predicting outcome of acute non-variceal upper gastrointestinal haemorrhage without endoscopy using the clinical Rockall Score. Postgrad Med J. 2006;82(973):757-759.

23. Masaoka T, Suzuki H, Hori S, Aikawa N, Hibi T. Blatchford scoring system is a useful scoring system for detecting patients with upper gastrointestinal bleeding who do not need endoscopic intervention. J Gastroenterol Hepatol. 2007;22(9):1404-1408.

24. Vreeburg EM, Terwee CB, Snel P, Rauws EA, Bartelsman JF, Meulen JH, Tytgat GN. Validation of the Rockall risk scoring system in upper gastrointestinal bleeding. Gut. 1999;44(3):331-335.

25. Pang SH, Ching JY, Lau JY, Sung JJ, Graham DY, Chan FK. Comparing the Blatchford and pre-endoscopic Rockall score in predicting the need for endoscopic therapy in patients with upper GI hemorrhage. Gastrointest Endosc. 2010;71(7):1134-1140.

26. Viriyaroj V. Predicting outcome of upper gastrointestinal bleeding without endoscopy using the clinical Rockall score and Blatchford. J Med Health Science. 2011;18(3):127-136.

27. Rockall TA, Logan RF, Devlin HB, Northfield TC. Incidence of and mortality from acute upper gastrointestinal haemorrhage in the United Kingdom. Steering Committee and members of the National Audit of Acute Upper Gastrointestinal Haemorrhage. BMJ. 1995;311(6999):222226.

28. Blatchford O, Davidson LA, Murray WR, Blatchford M, Pell J. Acute upper gastrointestinal haemorrhage in west of Scotland: case ascertainment study. BMJ. 1997;315(7107):510-514.

29. Bordley DR, Mushlin AI, Dolan JG, Richardson WS, Barry M, Polio J, Griner PF. Early clinical signs identify lowrisk patients with acute upper gastrointestinal hemorrhage. JAMA. 1985;253(22):3282-3285.

30. Lai KC, Hui WM, Wong BC, Ching CK, Lam SK. A retrospective and prospective study on the safety of discharging selected patients with duodenal ulcer bleeding on the same day as endoscopy. Gastrointest Endosc. 1997;45(1):26-30.

31. Corley DA, Stefan AM, Wolf M, Cook EF, Lee TH. Early indicators of prognosis in upper gastrointestinal hemorrhage. Am J Gastroenterol. 1998;93(3):336-340.

32. Zimmerman J, Siguencia J, Tsvang E, Beeri R, Arnon R. Predictors of mortality in patients admitted to hospital for acute upper gastrointestinal hemorrhage. Scand J Gastroenterol. 1995;30(4):327-331.

33. Imperiale TF, Dominitz JA, Provenzale DT, Boes LP, Rose CM, Bowers JC, Musick BS, et al. Predicting poor outcome from acute upper gastrointestinal hemorrhage. Arch Intern Med. 2007;167(12):1291-1296. 